\title{
Community-Based Development in Tari - Present and Prospects
}

\section{John Vail}

The current situation in Tari is very poor, following a long period of decline. The restoration of law and order, services, and infrastructure is a basic need. But this will not be adequate in itself. A community-based development approach, in which people participate in the improvement of their own living standards, is required if the rural stagnation underlying the current malady is to be overcome. The experience of the Family Health and Rural Improvement Program (FHRIP) and Community Based Health Care (CBHC) in Tari over the past eight years provides a model for development that can provide shared benefits and participation for all those involved.

However, considerable support is required if such initiatives are to grow and flourish. The Melanesian Farmer First Network, an innovative attempt to bring together a network of community organisations to assist one another, is one such source of support, but commitment to community-based development on the part of government and aid agencies is essential.

\section{The situation in Tari}

There has been a period of decline since the 1980s in the distribution and quality of services, and the state of law and order in Tari district. By September 2000, communications were not functioning, the road to Mendi was impassable except to police-escorted convoys, the bank and post office were closed, and the town power supply was not working (Family Health and Rural Improvement Program 2000). There was no doctor at the hospital, and several health centres and many rural aid posts were closed. Immunisation patrols had all but ceased. Several community schools had been destroyed or were closed, and most others were short of teachers. Agricultural extension services had long ceased functioning. Few public servants were at their posts in town. Almost no aspect of the administration was functioning properly.

In early 2003 things were no better. The last major retail/wholesale store in town had closed following the violence accompanying the 2002 election. The College of Distance Education centre had been razed. Widespread fighting had caused loss of life and destruction in the west and north of Tari. 


\section{Background}

Three interrelated problems characterise the situation in Tari: law and order breakdown, failure of service delivery, and rural stagnation. They have arisen over the past two decades from a complex of factors which are discussed below.

\section{Fighting and crime}

Inter-group warfare has increased both in scale and firepower over the past 15 years. Large-scale fighting re-erupted in the Tari basin in late 1986 after many years of relative peace. Since then battles involving many hundreds of warriors, some drawn from areas quite remote to the battleground, have become almost commonplace. In the mid 1990s firearms became widely used, increasing the number of fatalities and serious injuries in battles. The resulting, often inflated, compensation demands made conflicts harder to settle and fed into subsequent battles. In time, and in the absence of a suitable response by the authorities, recourse to arms reasserted itself as an acceptable way of dealing with disputes.

Criminal activity, especially roadblocks and robbery, has likewise increased in scale and violence, seriously affecting service delivery in many parts of Tari and Southern Highlands Province (SHP) generally. This activity is linked to tribal fighting, which creates an environment in which lawless activities can proliferate, entrenches a gun culture, and glorifies criminals who become 'folk heroes' in times of warfare.

The fighting itself has many causes. Most fights still arise from local matters. Population growth and an increasingly degraded environment in the less fertile areas (Yamauchi and Ohtsuka 2002) have exacerbated pressures on land and put people in closer proximity to each other, raising the number of everyday disputes and incidents. The increasing monetisation of the local economy is another contributory cause to crime and fighting. Roadblocks have become more common within Tari district in recent years, sometimes directly related to resource company payments. The Mt Kare gold rush in 1988 led to battles both at Mt Kare and in the Tari basin.

The corruption of the political process has also worsened the situation. The winner-takes-all nature of political contests has greatly raised the stakes in getting particular candidates elected. Over the years elections have become marked by a wide range of illegal practices, ranging from vote buying, rigging of electoral rolls, multiple and underage voting, to intimidation, violence and the hijacking of ballot boxes. Physical confrontation between supporters of rival candidates has resulted in death and destruction, the fighting in Tari town following the 2002 election being the most recent example. Political rivalry has also raised warfare to a new plane. In August 1999, a virtual 'civil war' broke out between Tari and Nipa districts following the death of a former provincial governor in a road accident. For a short period there was near-anarchy in Tari 
town, in which vehicles were hijacked and police-escorted convoys of men armed with shotguns circled the town before heading to the 'front' two hours east. Although the fighting was brought to a halt by the intervention of the provincial governor, Tari district remained largely isolated thereafter.

It should be emphasised here that warfare is usually a last resort, after mediation has failed. Many fights probably could be halted before they escalated if law enforcement authorities were active. Some battles have been defused by the intervention of police and district officers, but they are the exception rather than the rule. In general, attempts at suppression have been confined to punitive raids after the fighting has already caused destruction and loss of life.

Warfare must also be seen in its social context. For males at least, it is a participatory, inclusive activity. In a rural development vacuum, where men and youths have no organised, productive outlet for their energies, fighting brings an element of excitement in an environment in which there seems relatively little to lose. Few in Tari want to see a return to the era of endemic warfare, but few too have a realistic vision for a productive, peaceable alternative.

\section{Service delivery failure}

In the mid 1980s, most services in Tari were functioning. The road was open and passable and the town well supplied with consumer goods. The bank, post office and government offices were open. Power and communications worked most of the time, and were repaired when they broke down. Aid posts and health centres serviced remote areas, giving rise to excellent vaccination coverage of under five-year-old children. Schools were open and reasonably well looked after. But even at this relative highpoint, things were far from perfect. The public service was under-resourced and public servants did not, for the most part, venture far from town. Services in remote parts were less reliable than those nearer to the town.

The effects of public service shrinkage became obvious in the 1990s. Many different reasons have been advanced for this recession - under funding, mismanagement, corruption, politicisation, nepotism, lack of accountability, and lack of enforcement. Wherever the truth may lie, during the 1990s services began to be withdrawn from Tari town, and public servants retreated to provincial headquarters or simply failed to turn up at their offices. Morale among previously effective officers declined as their budgets were cut, despite a growing provincial budget. Equipment broke down, and was not repaired. Services declined further in remote areas. Aid posts were not staffed, teachers could not be found for classes. Roads and bridges were no longer maintained, and vehicles were misused or broke down. The public service largely ceased serving the rural population, and became instead a paid, town-based, elite serving mainly itself. 
Not all of this was due to internal problems in the public service. Crime and fighting damaged public infrastructure and made travel unsafe for public servants. Communications facilities on remote mountain tops were subject to compensation demands and pillaged or destroyed. However the decline in the effectiveness of the administration, police and village courts contributed to the general demise by allowing these lawless activities to continue unchecked.

By 2000 Tari had been denuded of almost all its functioning services, and even those most valued and resilient, health and education, had been reduced to a bare minimum due to a lack of supplies and personnel.

\section{Rural stagnation}

Stagnation rather than decline characterises the plight of rural areas in Tari. Away from the town, little change has occurred in material standards of living for many people over the years (Vail 2002b). Most families still live in bush materials dwellings with no water supply or sanitation. Few people have a range of nutritious crops in their garden, and most rely on sweet potato for their subsistence. Although the amount of money in the local economy has grown many-fold, due to the arrival of the highway in 1980, remittances from people working outside the district, and payments received directly or indirectly from the large resource projects surrounding Tari, the main result has been increased consumption of purchased goods, the price of which has risen steeply due to inflation and supply restrictions.

A number of reasons may be advanced as to why there has been so little rural development in Tari:

- Lack of productive economic activity. This in part arises from a lack of opportunity, due to unreliable prices for cash crops and distance to ports, but has been further undermined by crime, tribal fighting and the lack of maintenance of roads and public infrastructure.

- Lack of a suitable rural policy. In part this is due to a bureaucratic mentality that maintains a deep division between the lifestyles of paid public servants and subsistence villagers. More generally, there has been a failure to formulate practical policies allowing rural people to participate in development.

- An education system that is not geared to the majority who 'drop out' after six or ten years of school. Youths are educated in the expectation of paid work and ill-prepared for subsistence activities and community life.

- False expectations by rural people, who were led to believe that their role was a passive one in which goods and services were delivered by public servants and wealth handed out by those in power.

The result of the neglect of rural communities by the authorities has been disaffection and discontent. Failed expectations and income inequality are an 
oft-stated justification for the take-up of crime by youth. Likewise, few well-educated people are willing or prepared to work for and in their communities while rural conditions are so poor. Essentially, a vicious circle has been set up linking law and order problems, service delivery failure, and rural stagnation. Is there a circuit breaker?

\section{Community-based development}

While the restoration of government services and imposition of law and order are essential steps, alone they cannot solve the problems currently afflicting Tari and many parts of rural Papua New Guinea. A dynamic is needed that will involve people, especially youth, in constructive and fulfilling occupations. Their needs cannot be met through the formal sector and so an improvement in the quality of life for the rural majority must rely upon community-based development. In fact, the answer to many of Papua New Guinea's fundamental problems lies with making its rural communities attractive places to live.

First, what is community-based development? Simply put, it is a form of development that takes place within the community, emphasises maximum participation of community members in its design and implementation, is ongoing, meets real needs, and is basically self-reliant. To achieve this, the community needs to have a structure, and persons trained in appropriate methods of implementation. Usually, community-based development will be small-scale, low-cost, and use simple technologies. The model must be equally available to all communities, irrespective of their location, denomination or means, and provide for all members of the community according to their needs.

Much so-called development assistance is the antithesis of this. The predominant mode, service delivery, is in serious decline in rural areas. Even at its best it is expensive, non-participatory and inefficient. For example, community health workers, who are full-time public servants, rarely do more than dispense medicines for a few hours a day, and play no role in preventive health in the community they serve. An allied form of aid is the construction of objects, some useful, many not - for example, the council chambers built over five years ago in each sub-district of Tari, only to lie idle. Schemes may range from the political and grandiose - such as the proposed international airport for Tari - to the local and well-intentioned, such as village water tank installations; but most are expensive, rely on outside contractors, and lack sustainability. Another popular form of assistance is grants, often for small, local activities such as grass cutting along roads, or village livestock projects. The results are usually ephemeral and there is little or no accountability. The common thread in all such assistance is a lack of community involvement in the design, implementation and maintenance phases. 
Community-based development offers a way to improve on this, but not a simple or quick way. Communities in Tari are loose associations of people bound by kinship who live in proximity to each other. People come together for traditional purposes such as warfare, brideprice payments and compensation, but otherwise pursue fairly private lives. To organise them into functional bodies capable of understanding community needs and able to pursue the means to satisfy them takes considerable time and effort. For community-based development to occur people must adopt a new attitude, in which they become actors rather than recipients, and embrace small incremental change generated internally rather than expect large infusions of external wealth and technology.

The issue of water supply in Tari may be used to illustrate the different approaches. Often community water supply is taken to mean a large tank built in a central location such as the local aid post. However there are problems with this approach. First, while people may be able to obtain adequate quantities of drinking water from the tank, there is also a need for water for cleaning, cooking and washing. Most families will be too far away to benefit for these purposes. Secondly, if the tap is damaged, there may be no one prepared to take responsibility for repairing it. The tank is left idle while people argue about who was to blame and send requests to the donor to come and fix it. Hence costs may be high, benefits low and needs left unmet. A better solution for people living in scattered homesteads is likely to be small low cost units that are owned by individual families, and supply water on their doorsteps for all their domestic needs. To choose this mode of water supply, the community must obtain materials, train volunteers, and prioritise among families in terms of need. Families in turn must invest some of their own money, materials and labour in obtaining a water supply unit, and maintain their own units. By this method needs are better met, there is more participation, and more ownership. But the community must be organised and able to weigh the costs and benefits, not passively allow the choice to be made for it.

Hence community-based development encompasses forms of development as well as the structures needed to achieve them: it is biased in favour of participatory, community-controlled methods. The Family Health and Rural Improvement Program (FHRIP) was one initiative designed to address key community needs at the lowest level using simple low-cost methods and technologies, and training local people to run and implement the program. It hoped not only to improve the quality of life for families but also engage communities in constructive enterprise, making them less likely to be drawn into the self-destructive activities witnessed in Tari and many parts of the highlands over the past decade. 


\section{The Family Health and Rural Improvement Program}

FHRIP started life in 1995 as the Nutritional Garden and Household Improvement Program, using the resources of the Papua New Guinea Institute of Medical Research and funding from Porgera Joint Venture. The basic aims of the program were to improve family health, particularly through preventive means, and to stimulate small-scale rural enterprise. Initially the network of Institute of Medical Research demographic reporters was used as the interface with the community. As time went on, and a more community-oriented approach was adopted, voluntary groups replaced individuals.

The components of the program were water supply, sanitation, nutritional gardens, small livestock, and health education. Each element embodied a degree of innovation. Water supply units were designed to be cheap, portable and easily constructed. They were made chiefly of bush materials, using a plastic sheet for catchment and a 400 litre bag with snap-on tap as storage. The water supply was placed as close as possible to the house of the mother and children, who were the intended principal beneficiaries. The sanitation component consisted of a pit latrine with a tapered concrete block and a bucket, which together with the water supply unit enabled the latrine to be kept clean. The key aim of the nutritional garden was to provide a supply of protein and greens close to the family home and therefore readily available to be included in meals. To some extent it was an extension of the 'kitchen garden' that surrounds most village homes, with the inclusion of a range of protein-rich crops such as soybeans, peanuts, lablab beans and pigeon peas. To reinforce their use, cooking demonstrations were held at a community level to familiarise families with the crops and the best ways of cooking them.

Composting was encouraged as a means of sustaining yields. FHRIP also promoted mixed crop/livestock farming, which was run successfully at its agricultural resource farm at Koli for many years. Among the animals kept there were chickens, ducks, rabbits, sheep and goats. These animals were supplied to program families at subsidised prices according to certain conditions. For example, a pen was required before Australorps chickens could be purchased. Similarly, cages were constructed in the workshop and supplied with rabbits to new farmers. And as well as supplying lambs and kids, FHRIP co-coordinated the breeding program to ensure the quality of stock was maintained. By applying these conditions, and an ongoing program of extension, the chances of success in village livestock-keeping ventures were enhanced.

Under the health education component, female health extension workers visited families to explain the relationship between hygiene, nutrition and the prevention of disease, discuss family health problems, and train the family to properly use the small kit provided by the program. The kit contained buckets and a brush, to help the family make best use of their water supply, and swabs 
and antiseptic ointment so that mothers could treat their children's sores and cuts at home and prevent them from becoming clinical problems.

The program was both integrated and phased. In order to join the program, each family had to agree to implement the entire phase one, consisting of water supply, toilet and nutritional garden. Only when they had achieved satisfactory results with these components were they allowed to proceed to phase two, in which they could acquire small livestock or roofing iron for a 'permanent' water catchment.

In order to run the FHRIP program, a team of local workers was assembled and trained. They in turn trained community workers, either singly or in groups, as female local health promoters or male local assistants. These community workers then assisted families to construct program items, delivered preventive health kits, and made regular visits to check progress and discuss health matters. Over 60 community workers were trained between 1995 and 2000. Each participating community constructed a 'support station' at which tools were kept and seeds and livestock propagated. These support stations enabled local workers to take more responsibility for running their own program as time went on.

The Papua New Guinea Institute of Medical Research office in Tari was the administrative centre and workshop for the program, while Koli farm served the role of agricultural resource, training and demonstration centre. Innovations used in the program were developed at these sites. In addition to the major components such as the water supply unit and concrete blocks, seed storage cupboards and driers, cane brooms, chicken feeders, rabbit cages and many other items were designed and distributed to families and support stations.

The cost of running the program in 2000 was approximately K118 (\$A60) per new family for the basic inputs of water supply, toilet and nutritional garden. Cost of livestock including fencing material or pens was around K150 per family. The phase one preventive health inputs were provided free of charge while livestock and roofing iron were provided in prescribed quantities at subsidised prices. A community support station, complete with tools and shed, cost around K1150. Other costs involved in running FHRIP (excluding capital items) amounted to about K60,000 per annum. Wages for FHRIP team members accounted for the majority of this, the remainder being divided between vehicle, administration, resource stations and training.

\section{Results}

A total of 312 families participated in the program between 1995 and 2000. This represents about 10 per cent of all target families in the Tebi, Tagari and Haeapugua sub-districts of Tari. Figure 9.2 shows the distribution of families in the program whose location was recorded by GPS (Vail 2002a). 
Sixty-one families (20 per cent) left the program or were dropped, either for their own reasons or due to external circumstances such as fighting. Of those still in the program in April 2000, 195 families were ranked according to a point score that measured the number and condition of program components each family had acquired. By this measure, 143 families (73 per cent) were rated as doing well, while the progress of 23 families (12 per cent) was regarded as unsatisfactory.

While it is difficult to demonstrate that general health improved as a result of participation in FHRIP, it is fair to say that families with a supply of clean water, a well-kept toilet and nutritious crops in their garden are better able to meet their basic needs than those, the majority, who do not. There were many individual examples of families who became better off because of their participation in the program. Those who acquired small livestock took the first step towards the more diversified and productive local farming system that will be needed if the challenges of environmental degradation and population growth are to be met in the coming years. The additional labour input required also provides potential employment for underemployed youths and men.

\section{Figure 9.1. Distribution of FHRIP families 1995-2000}

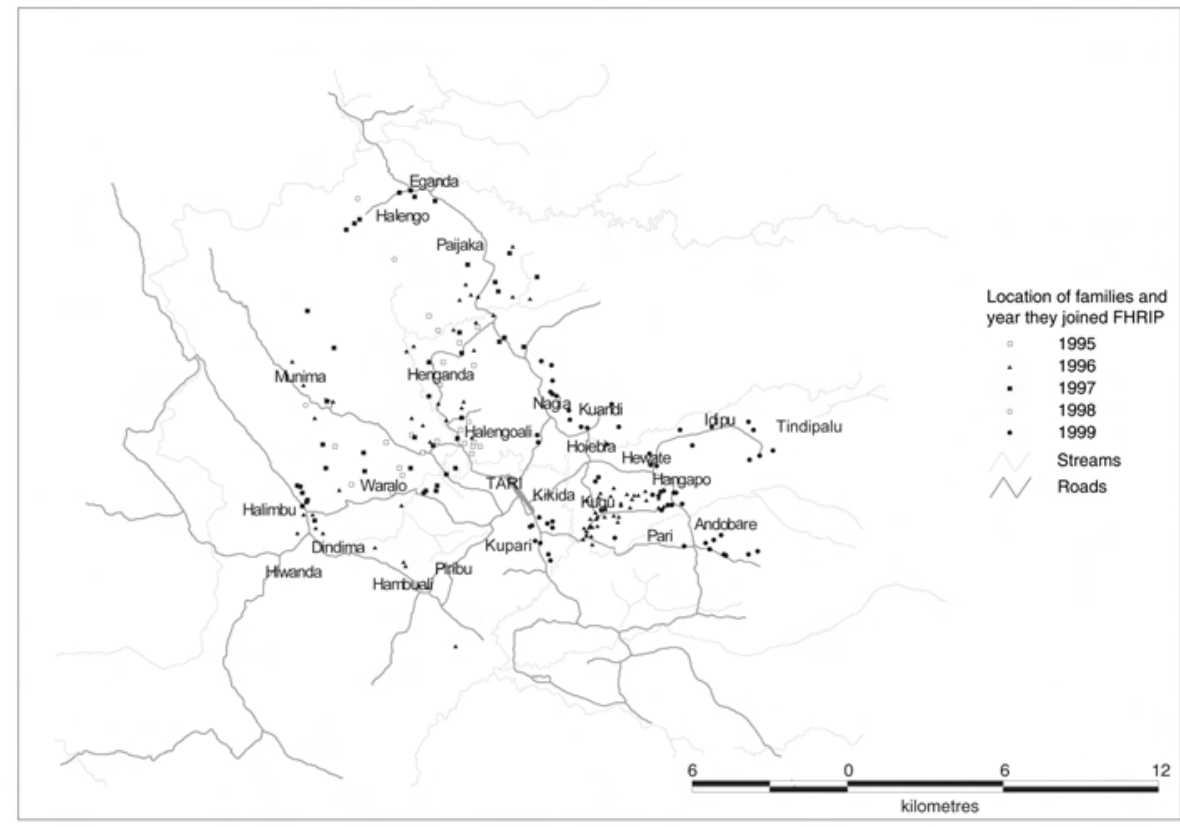

In terms of individual program components, the water supply unit proved to be fairly robust in a family setting. The main problem was the deterioration of the plastic sheet used as a catchment, which had to be replaced after about six months to one year. Rabbits were slow to be accepted, but became 
increasingly valued and popular among people in the program and outside it. By area, the best results were in the western parts of Tari, where excellent local program leadership provided an inspired role model for peers. On the other hand, nutritional gardens did poorly in the more remote, environmentally degraded areas to the north of Tari. In the east, local voluntary groups ran most programs, and results depended upon their organisation and commitment.

These mixed results illustrated a flaw that became increasingly evident as time went on. Because most communities lacked an internal structure capable of running a diverse and challenging set of activities, the burden was placed upon individuals, groups, and the FHRIP management team, rather than the community as a whole, to keep the program running. Hence FHRIP satisfied only in part the prerequisites of community-based development - it offered forms and inputs but lacked the capacity to build a structure in the community able to take advantage of them.

FHRIP survived the strains placed upon it by breakdowns in law and order, communications and transport, but the decision to close the Tari branch of the Institute of Medical Research in 2000 meant that a new operating arrangement would be required if the program were to continue. FHRIP had been cooperating with Community Based Health Care (CBHC) for some time, and in September 2000 a partnership was formed under which CBHC provided management and a new direction, based on their experience in Tari and other highlands provinces.

\section{Community-Based Health Care}

CBHC, a division of the Nazarene Health Ministries, commenced working with community groups in Western Highlands Province in 1995, and over the next five years expanded into neighbouring highlands provinces. Their principal aim is to provide holistic health care for communities through preventive, curative and health promotion activities. More generally, CBHC encourages communities to become self-reliant, self-regulating and productive. To do this CBHC embarks upon a comprehensive program of awareness raising, capacity building and training. Each community is assisted to establish a health and development committee, comprising local councilors, peace officers, and clan, youth and women leaders, to coordinate their development plans. These plans are then devolved to the clan level, at which volunteers implement the program activities and construct a focal meeting house at which local needs and issues are discussed for consideration by the committee. Communities must attain set minimum standards, in respect of family hygiene and community unity, to be accepted as a CBHC community and qualify for further assistance. The ultimate goal is the declaration of the community as a 'Healthy Village' after meeting all the set requirements. 
The structure of a CBHC-trained community is as shown below (Nazarene Health Ministries 2002).

\section{Figure 9.2. CBHC structure}

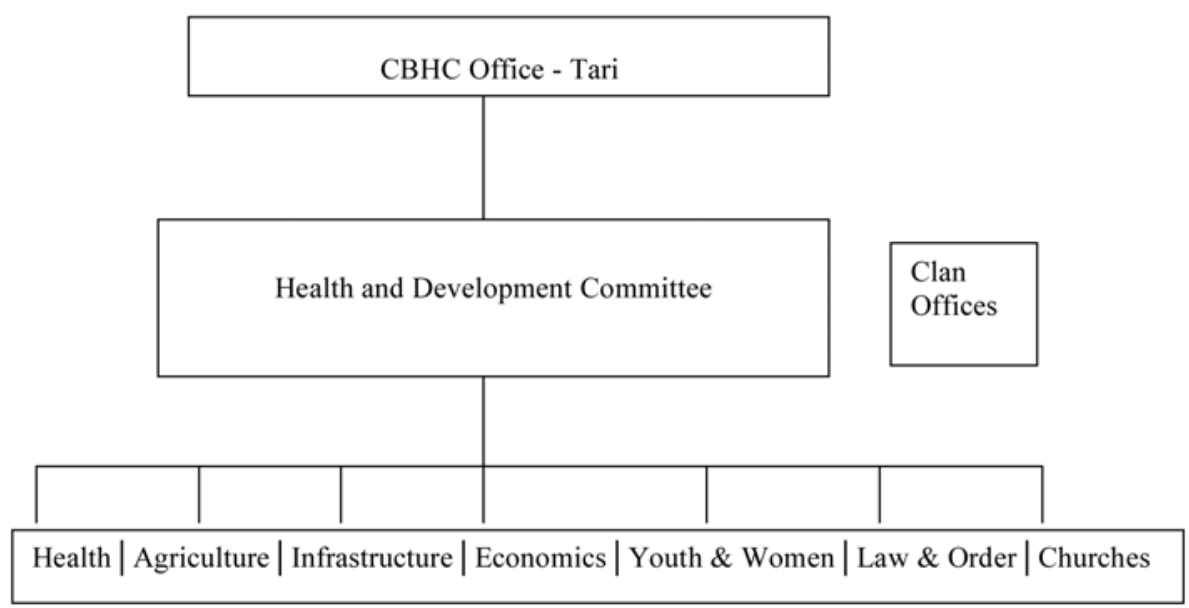

In late 1999 CBHC started working with the Pari-Andoware community in the east basin of Tari. Many of the activities shown in Figure 9.2 have been set in action since. Under the key health component, CBHC trained village health volunteers to dispense first aid drugs, and village birth attendants to perform deliveries. Arrangements are made with the Maternal and Child Health program nurses to visit communities so that the target of over 80 per cent vaccine coverage for women and children is attained. Under the law and order activity, two village police officers were trained to work in cooperation with the law enforcement authorities. The infrastructure program covers repairs to local roads and bridges through community participation. Among the agricultural activities were the procurement of coffee seedlings, arrangements with coffee buyers to visit communities, and the import of fingerlings for family fish ponds. There is also a small-scale project facility which provides seed money for projects on a 40/60 ratio of $\mathrm{CBHC}$ to the local community. At the household level a community cooperative credit scheme has been established to promote savings and loans for basic household needs.

By April 2003 CBHC was supporting six communities in different areas of the Tari basin. Each new community inducted into the CBHC program is regarded as a role model for others to follow. $\mathrm{CBHC}$ trains 'trainers of community health volunteers' from among these communities so that there is the capacity to induct new communities that have expressed peer interest in becoming part of the program. 
In order to introduce a more community-oriented approach into the national and provincial health departments, CBHC runs training courses for government health workers at its headquarters in Western Highlands Province. Some CBHC training positions are funded by the Health Department. CBHC involves itself closely in district management committees and seeks partnerships with government departments, missions and other organisations assisting community development.

\section{CBHC/FHRIP partnership}

Since the merger of CBHC and FHRIP in September 2000, FHRIP has been integrated into its partner's management structure. FHRIP no longer pursues an independent program but works alongside $\mathrm{CBHC}$ communities, training local volunteers in water supply construction, seed propagation and small livestock management, and supplying the initial needs of communities in respect of these items from its resource station. FHRIP workers have also been instrumental in initiating new communities into the CBHC program. While the partnership has not been without its tensions, the pooling of resources and experience by these two highly complementary organisations has strengthened their capacity to support community-based development in Tari. The fact that six communities, comprising hundreds of families, are now part of the CBHC program, indicates both the commitment of the management and the desire for development among rural people.

However the relative success enjoyed by CBHC/FHRIP over the past eight years should not be taken to mean that such local organisations can run their programs without support or resources. On the contrary, appropriate assistance, financial, technical and managerial, strengthens their capacity to reach more communities sooner. The Melanesian Farmer First Network provides one means by which such assistance may be provided.

\section{Melanesian Farmer First Network}

The Melanesian Farmer First Network (MFFN) represents a coming together of community-based organisations in Papua New Guinea and elsewhere in the Pacific to share experience and expertise among themselves. It is predicated on the idea that organisations with similar goals and methods, working in culturally similar environments, should be able to exchange ideas and practices for their mutual benefit. It also represents an attempt to move away from undue reliance on costly Western-based advisors and methods as the primary source of development assistance.

The concept of MFFN was developed by Terra Circle, a group of persons with wide development experience at the community level in the Pacific, and is co-coordinated by the Kastom Gaden Association in Honiara, Solomon Islands. The initial MFFN partners are Kastom Gaden Association, Planting Material 
Network (based in Solomon Islands), CBHC and Paruparu Education Development Centre (on Bougainville). An inaugural meeting of the partners was held in Tari in April 2003. Among the objectives of MFFN are:

- to strengthen the technical and management capacity of non-government and village organisations to implement their programs, particularly in respect of food security;

- to help local organisations meet their needs for information, education and communications through appropriate methods;

- to develop low cost networks linking government departments, regional and international organisations, NGOs, and farmers and village organisations (Kastom Gaden Association et al 2002).

In Tari, MFFN is supporting training, capacity building, and exchanges, using the resources and expertise it has within the network. As an example, a worker from Tari has recently visited the Kastom Garden Association and Planting Material Network in Solomon Islands to learn seed saving methods, which she will put in practice to assist $\mathrm{CBHC}$ communities to improve their seed multiplication and storage methods. To improve communications, MFFN is currently looking into acquiring an HF radio modem to provide an email link between $\mathrm{CBHC}$, other partners in the network, and the wider world. Other exchanges are planned in which CBHC/FHRIP staff will play a training role, which will involve strengthening the management capacity of each of the organisations involved.

\section{Program requirements}

Although MFFN, which has limited start-up funding from Oxfam/Community Aid Abroad, can provide technical support, considerably more assistance is required, both financial and material, if the CBHC/FHRIP program is expanded to meet the needs of the many communities in Tari/Komo-Margarima and Koroba districts interested in joining. Priority areas are:

- Funding. The current funding cycle for the wages of FHRIP team workers, negotiated with New Zealand Overseas Development Agency in 2000, comes to an end in October 2003. Without a renewed commitment a dozen staff will have to be laid off, causing the loss of valuable skills and experience, and weakening the vital implementation end of the program. CBHC will also require funding for additional training positions as the program expands.

- Management capacity. Currently there is an over-reliance on key individuals in the program. More persons need to be trained in management techniques to reduce this burden.

- Communications. The unreliability of communications with the outside world has been a major obstacle to acquiring program inputs, networking with other organisations and keeping in touch with donors. 
- Transport. The poor quality of the roads, dispersed nature of the communities, and lack of facilities for service mean that wear and tear on vehicles is high. As the program expands vehicle replacement and maintenance costs will rise.

- Improved monitoring and evaluation skills. Participatory appraisal methods together with better record-keeping will mean the program is better able to identify program strengths and weaknesses and act upon them.

- Upgrading of the resource station to enable it to fully meet its functions as supplier of seeds and livestock, training and demonstration centre. A volunteer is being sought to assist with the management of the resource centre.

Other needs also exist, in the areas of office space and equipment, and tools and materials for use in the communities.

\section{Conclusion}

Community-based development has been badly neglected in Southern Highlands Province and in Papua New Guinea generally over the past two decades. Greater inclusiveness and participation by communities in the development process may hold the key to the long-term solution of many of the problems besetting the rural areas of Papua New Guinea. More engagement by youth in their local community reduces the potential for frustration and discontent that underlies the law and order problem. Better functioning communities, meeting more of their own health, law and order and development needs, reduces the load on the public service, providing it with more space for reform and revitalisation. More productive communities also diminish the economic imperative to migrate to the towns and hence counteract the imbalance that will grow for as long as rural areas remain stagnant and neglected.

Such development is by its nature very management-intensive and must be nurtured; it cannot be 'delivered' by outside agents in large technical downloads. It need not be very costly in monetary terms but it does require adequate resources to grow and flourish. The worst outcome is to starve promising initiatives of the means they require to assist communities, as this demoralises local program workers and leaves communities ever more bewildered about what development actually means.

The government and aid organisations need to recognise the importance of community-based development and include organisations like CBHC/FHRIP with proven track records in district and national plans, not just to provide funding but also to secure the commitment of public servants to work innovatively alongside these organisations, in the community, to meet rural needs that are currently not being met. 
More generally, there needs to be greater attention focused on the internal generation of wealth, through local markets, trading networks and exchange systems. While this does not preclude agricultural and extractive industries as sources of income, it should be recognised that export-led growth is but one means of development, and one which has not worked well in the past. In one sense, the future of the highlands of Papua New Guinea may lie in the past a return to more self-reliant, more self-contained systems, but less insular than before, learning from each other's knowledge and experience, and based upon well-ordered and well-managed communities.

\section{References}

Family Health and Rural Improvement Program. 2000 Combined Quarterly Reports for April-June \& July-September 2000. Tari: Papua New Guinea Institute of Medical Research.

Kastom Gaden Association, Planting Material Network, Family Health and Rural Improvement Program, Paruparu Education Development Centre and the Farm-Support Association. 2002 Farmer First: A Pacific Food Security Network of Melanesian Community Organisations. Solomon Islands: Kastom Gaden Association.

Nazarene Health Ministries. 2002 Community Based Health Care Program Strategic Plan 2003-2005. Kiam WHP: Community Based Health Care Program.

Vail, J. 2002a 'The Family Health and Rural Improvement Program', Papua New Guinea Medical Journal 45(1-2):147-162.

2002b 'Social and economic conditions at Tari', Papua New Guinea Medical Journal 45(1-2): 113-127.

Yamauchi, T. and Ohtsuka, R. 2002 'Nutritional adaptation of women in contrasting agricultural environments in Tari, Papua New Guinea', Papua New Guinea Medical Journal 45(1-2): 99-105. 